\title{
Cidade, territorialidade e redes na política de saúde mental
}

\author{
Luciana Assis Costaa ${ }^{a}$ Flávia Duque Brasil ${ }^{b}$

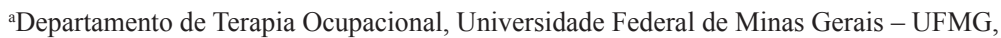 \\ Belo Horizonte, MG, Brasil

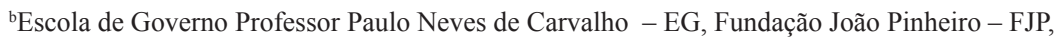 \\ Belo Horizonte, MG, Brasil
}

\begin{abstract}
Resumo: A concepção de território, evidenciada pela municipalização e desinstitucionalização da saúde, torna-se elemento fundamental na construção do modelo substitutivo de saúde mental. O objetivo deste estudo é compreender como a política de saúde mental reaproxima-se do âmbito local, de forma territorializada, para desenvolver estratégias de assistência que corroboram o novo modelo de saúde mental. A partir disso, refletir sobre as possibilidades de reconstrução de novas relações sociais que possam de fato ampliar o pertencimento das pessoas com sofrimento mental na sua forma de convivência mais ordinária. Trata-se de um ensaio que utiliza como aportes teóricos referenciais e conceitos das Ciências Sociais, retratando as diferentes visões das principais escolas da Sociologia Urbana para a compreensão do território em suas múltiplas concepções e possíveis relações com a área da saúde mental. A série histórica dos dados sobre a saúde mental no Brasil demonstra que a política de saúde mental avança de forma heterogênea nas diferentes regiões brasileiras. Por fim, o cabimento da loucura na cidade depende de uma efetiva expansão dos serviços de saúde mental de bases territoriais, bem como de ampliação do acesso a bens e serviços não necessariamente atrelados à saúde mental mas aos direitos sociais básicos de cidadania. Espera-se que novas regras sociais de relacionamento não se restrinjam ao universo da saúde mental mas que promovam novos encontros no espaço urbano, marcados pelo respeito à diversidade e às diferenças.
\end{abstract}

Palavras-chave: Serviço de Saúde Mental, Territorialidade, Política Pública.

\section{The city, territoriality and networks in mental health policies}

\begin{abstract}
The understanding of territory, made evident by a decentralized, local based, and non-institutionalized mental health model, is a fundamental element in building a renewed network. The objective of this essay is to understand how mental health policies gradually favor local actions, organized in terms of territories, to develop strategies of care that support the new model of mental health. From this perspective, the aim of this research is to reflect on the possibilities of establishing new social relations that can, in fact, widen the sense of community belonging in the daily living of those presenting mental health conditions. This study draws from theoretical concepts and frameworks of the social sciences, describing the diverse positions held by the main schools of urban sociology with regards to the understanding of territories. The multiple conceptions of territories and their relations to mental health are analyzed. Historical data about mental health in Brazil show a heterogeneous development of mental health policies in different areas of the country. Finally, social inclusion in the cities depends on an effective expansion of territory-based mental health services, as well as an amplification of the access to consumer goods and services not necessarily connected to health care, but to basic social and civil rights. Hopefully, new rules of social interaction will not be restricted to the mental health universe, but will promote new encounters in the urban space, with respect for differences and appreciation of diversity.
\end{abstract}

Keywords: Mental Health Service, Territoriality, Public Policy.

Autor para correspondência: Luciana Assis Costa, Departamento de Terapia Ocupacional, Universidade Federal de Minas Gerais, Av. Antônio Carlos, 6627, Pampulha, CEP 31270-901, Belo Horizonte, MG, Brasil, e-mail: lucianaassis.ufmg@gmail.com

Recebido em 4/12/2012; $1^{\text {a }}$ Revisão em 6/5/2013; $2^{a}$ Revisão em 30/8/2013; Aceito em 16/9/2013. 


\section{Introdução}

A dimensão do território e da cidade tem adquirido relevo nos debates contemporâneos sobre as políticas sociais. Os déficits históricos de inclusividade apontam o reconhecimento da complexidade e multidimensionalidade dos problemas sociais que requerem enfrentamento mais calibrado pelas políticas sociais e suas novas agendas.

No caso brasileiro, a partir do contexto da redemocratização, destaca-se a atuação dos movimentos sociais, suas redes e outras organizaçôes societárias que impulsionaram avanços nas políticas públicas e marcos legais, encampando diretrizes de democratização, descentralização, inclusão social e alargamento dos direitos sociais expressos na Constituiçáo Federal de 1988 (CF-88). Afirmaram-se como princípios e diretrizes que balizaram as políticas sociais a universalidade e integralidade, a democratização por meio da criação de canais de participaçáo e a descentralizaçáo. A dimensão $\mathrm{da}$ cidade ganhou ênfase não apenas pelo vetor $\mathrm{da}$ descentralização e da ampliação de autonomia local, mas também pela tematização da territorialidade e $\mathrm{da}$ intersetorialidade como chaves no enfrentamento da complexidade das questôes sociais.

Nas políticas sociais, construíram-se agendas reformistas que implicaram sua reconfiguração. No caso do Sistema Único de Saúde (SUS), a legislação é aprovada no início dos anos 1990, já a aprovação da Lei de Reforma Psiquiátrica envolveu um trâmite longo. A referida legislação confluiu na política nacional de saúde mental, resultado de um intenso movimento societário em prol da reorientação do modelo psiquiátrico, tendo a desinstitucionalização da assistência o seu ponto nuclear.

No que tange à política de saúde mental, a dimensão do território e a territorialização assumem uma maior amplitude, pois o modelo atual prioriza o espaço urbano e o território como lócus de reconstrução da sociabilidade e inclusão social das pessoas com sofrimento mental.

Nesse bojo, a cidade e o território têm sido tematizados na construçáo e recodificação do lugar social da loucura. A concepção de território torna-se elemento fundamental na construção do novo cenário da saúde mental, a partir das diretrizes de descentralização, de municipalização e de desinstitucionalizaçáo e na possibilidade de uma perspectiva mais abrangente de territorialização. Isso justifica, para este ensaio, mobilizar referenciais das Ciências Sociais. Recorre-se especialmente à sociologia urbana, pelo seu esforço sistemático e focalizado no urbano, como lócus de tensão e potencialidades para se pensar, na expressão de Lobosque (2007, p. 35), o "cabimento da loucura na cidade".

Busca-se compreender como a política de saúde mental reaproxima-se do âmbito local de forma territorializada, enfatizando-se a dimensão do território em suas múltiplas concepções. Tem se em vista contribuir para aprimorar estratégias de assistência que corroboram a reconstrução de novas relaçôes sociais que possam de fato ampliar o pertencimento das pessoas com transtorno mental em sua forma de convivência cotidiana.

Assim, na primeira seção apresenta-se uma breve revisão de como a cidade é abordada na sociologia urbana, retratando as visóes das principais escolas que constituíram esse campo e aportam diferentes elementos para compreensão do território e da cidade, quais sejam, a escola de Chicago e a escola marxista francesa. $\mathrm{Na}$ segunda seção, recorre-se a outras referências que abordam a cidade e as redes sociais territorializadas, esboçando liames com as políticas sociais. A terceira seção aborda de forma sumária o processo de reforma psiquiátrica, fundamentado no paradigma da desinstitucionalização, que elege a cidade como espaço social da assistência e de construçáo da cidadania do doente mental. Por fim, a rede de serviços de saúde mental é apresentada, destacando o papel do Estado na ampliação dos espaços de circulação e pertencimento do usuário no território, considerando a saída dos equipamentos hospitalares como estratégia essencial para novas práticas cotidianas.

\section{A cidade (re)construída sob diversos olhares}

A cidade comparece em reflexôes nos diversos campos, desde perspectivas entre os séculos XIV e XVII, nas quais as utopias de uma sociedade igualitária encarnavam-se em propostas assumindo a dimensão espacial como um fundamento de igualdade. Os processos de constituição da sociedade moderna e capitalista, imbricados com a urbanização, associam-se a novas reflexóes críticas, inclusive sobre as condiçōes de vida da população. Marx (com Engels) e Weber produziram diagnósticos críticos da modernidade emergente (seja, respectivamente, modelada pelo capitalismo ou pelo processo de racionalização) e não deixaram de referenciar a questão urbana. Embora Marx não tenha produzido reflexóes robustas sobre a cidade, constituiu uma das chaves de abordagem influente. Dentre os clássicos, podem ser mencionados, também, autores no campo 
da teoria democrática, que embora não se detivessem na dimensão espacial, enfatizaram a esfera local para a construção da democracia.

O ensaio A metrópole e a vida mental, de Georg Simmel - de 1903 -, é emblemático no campo dos estudos urbanos, detendo-se nas consequências psíquicas da vida urbana, apontando a prevalência das relaçôes secundárias e o caráter superficial e pontual das interaçôes, a segmentação de papéis, o individualismo e um padrão de comportamento indiferente, em virtude do excesso de estímulos do meio urbano (BRASIL, 2004). Simmel constituiu lastros para escola de Chicago, que no período entre guerras abre o campo da sociologia urbana, marcando-se por análises empíricas interpretativas. Em sua vertente culturalista, a cidade é abordada como um quadro sociocultural: a cidade produziria cultura e sociabilidade urbanas e modernas, contrapostas aos modos de vida tradicionais. Enfatiza-se, portanto, a relação da cidade com as formas de sociabilidade. No que toca à estrutura espacial, produz modelos analíticos, como a diferenciaçáo centro-periferia, ainda relativamente aplicável.

Entre os anos 1960 e 1980, a escola marxista francesa recoloca sob premissas a reconstrução crítica do espaço urbano, reconhecendo sua historicidade, ao compreendê-lo como produto das relaçôes de produção capitalista, lócus de reprodução da força de trabalho e como condição de acumulação capitalista (BRASIL, 2004).

Essa reconstrução do urbano ilumina a dimensão política e conflitual nos processos de (re)produção capitalista do espaço a partir dos diferentes agentes. Os movimentos sociais são tomados como agentes de mudança, contestação e inovação, configurando-se a noção de movimentos sociais urbanos, referidos às lutas relacionadas ao consumo coletivo e à ordem socioespacial.

Enquanto os teóricos da escola de Chicago destacam o espaço como um elemento que modela as relaçóes sociais, os neomarxistas sublinham o espaço como produto das relaçóes capitalistas, evidenciando a exclusão e as desigualdades sociais e socioespaciais - que se conjugam com assimetrias de poder político entre os segmentos sociais e rebatem-se nas políticas.

Lefebvre foi um dos pilares da escola neomarxista e soma aportes da fenomenologia ao apresentar o urbano também como espaço do cotidiano, encontros e trocas, da festa e simultaneidade. Considerando que a existência humana se estrutura a partir das dimensões da historicidade, da sociabilidade e da espacialidade, sua noção de espaço social destaca o espaço não apenas como produto das relaçóes sociais, mas também como a condição e meio de (re)produção dessas relaçóes, articulando práticas espaciais e dimensóes vividas, percebidas e imaginadas (LEFEBVRE, 1994). Nessa "pegada” fenomenológica, que remete à experiência cotidiana dos sujeitos e construção da realidade social, Certeau (1996) efetua a distinção entre espaço e lugar: o lugar como espaço apropriado, portanto, indissociado dos sujeitos.

Também Santos (2000) reconhece que o espaço é socialmente construído tanto quanto as relaçôes sociais são espacialmente constituídas. O autor destaca o espaço da cidadania, na perspectiva dos direitos e de constituição de sujeitos políticos, e o espaço da comunidade, ancorado nas relaçôes cotidianas e organizaçóes societárias de base. Essas relaçóes produzem e reproduzem os territórios físicos e simbólicos, as identidades e identificaçóes com referências às origens e destinos comuns. Nos termos do autor, a dimensão do espaço da comunidade é especialmente relevante para a provisão da proteçáo social nas sociedades periféricas.

Em síntese, ressaltamos contribuiçóes gerais dessas referências para problematizar a política de saúde mental. A partir da escola de Chicago, destaca-se a cidade como lócus de sociabilidade, no qual, a partir das interaçóes e redes sociais, desenham-se territorialidades. Assim, pode-se considerar que a apropriação da cidade pelo usuário de saúde mental potencialmente transborda o circuito de acesso aos serviços e redes de assistência.

Sob as lentes neomarxistas, refletir sobre a cidade no mínimo significa considerar a organização socioespacial desigual e excludente. Coloca-se a questáo de como amplificar as dimensóes inclusivas da política de saúde mental num quadro socioespacial de "des-cabimento" de uma ampla parcela da população nas cidades, com dificuldades de acesso ao trabalho, moradia digna, serviços e equipamentos urbanos, sociais, de lazer e de cultura, transporte e mobilidade (BRASIL, 2010). A própria espacialização dos equipamentos dos serviços e redes de atenção à saúde mental consiste em uma questão crítica em face das desigualdades socioespaciais.

A partir de Lefebvre abrem-se questôes de como a cidade em seus espaços públicos propicia ou desfavorece reapropriações do espaço, inclusive inusitadas e lúdicas. A partir de Boaventura de Sousa Santos, aponta-se para o lugar da cidadania e da comunidade, mediante a construção de representaçóes e o estabelecimento de laços sociais territorializados.

Em seguida aborda-se a dimensáo da cidade e de seu espaço social como problema, mas também 
seus potenciais associados às redes de sociabilidade, mobilizando-se aportes da literatura das políticas sociais.

\section{Cidade e redes de sociabilidade territorializadas}

A dimensão espacial apresenta-se como problema no que se refere às desigualdades, processos de exclusão e segregação, notando-se a sobreposição entre as desigualdades socioeconômicas e socioespaciais que se revela na espacialização das classes sociais, conformando áreas elitizadas em contraste com um tecido em que constelam precariedades e déficits de inclusividade socioespacial, como as periferias e as áreas de ocupação informal.

A dimensão espacial, em si, consiste em um fator de reproduçáo das desigualdades e da pobreza, na medida das precariedades e da limitação das oportunidades. Nesse sentido, Lupton e Power (2002) exploram a relação entre exclusão social e vizinhança, notadamente a concentração de segmentos desprivilegiados em áreas mais precárias. Afirmam que as características de localização, base econômica, acessibilidade aos serviços e equipamentos urbanos, padrão habitacional impactam as atitudes, os comportamentos e as interaçóes. Já Paugam (2003) refere-se à construção de uma imagem negativa e à desqualificação de determinadas áreas da cidade, náo sustentando, entretanto, um destino selado das áreas multidegradadas, em virtude das possíveis redes de sociabilidade e das mobilizaçóes que podem ancorar a construção de identidades coletivas. $\mathrm{O}$ autor observa nos segmentos sociais fragilizados um processo de deslocalização social e de aprendizado da desqualificação social, de perda das referências de identidade, que se revelam no isolamento progressivo e no recuo para a esfera das relaçôes domésticas, mas também nota que a proximidade geográfica pode estabelecer um conjunto de práticas, apontando para as redes de solidariedade evidentes.

As potencialidades das redes de sociabilidade territorializadas são tematizadas também por Magnani (1987, p. 128), que destaca a importância das redes sociais especialmente para os grupos vulneráveis. O autor cunha a noção de "pedaço", composto pela dimensão espacial que ancora a sociabilidade e a construção de redes de relaçóes sociais. No pedaço

[...] se tece a trama do cotidiano: a vida do dia a dia, o desfrute do lazer, a troca de informaçôes e pequenos serviços, os inevitáveis conflitos, a participação em atividades vicinais.
Koga (2003, p. 33) apresenta o território como o chão concreto da vida cotidiana, das políticas públicas e do exercício da cidadania, onde

[...] o direito a ter direitos é expresso, negado ou reivindicado a partir de lugares concretos: o morar, o estudar, o trabalhar, o divertir-se, o viver saudavelmente, o transitar, o opinar, o participar.

Os autores mobilizados focalizam áreas precárias e grupos vulneráveis para os quais a dimensão socioespacial se coloca como problemática, mas também revelam potenciais de articulação de redes de sociabilidade e solidariedade. Essa linha de reflexão pode ser considerada para pensar as políticas sociais sob o ângulo das dimensóes do cotidiano, da inscrição das relações sociais no espaço. No caso da política de saúde mental, o território tem sido eleito como critério de organizaçáo de práticas e serviços por meio de esforços locais e intersetoriais. Busca-se incorporar em seu desenho as redes de sociabilidade das áreas de intervenção, por diversos caminhos que convergem para a expansão dos laços sociais do usuário na cidade.

O desafio da política de saúde mental, como apontado por Lobosque (2007), náo se restringe ao aspecto terapêutico, que implica oferecer um tratamento digno aos chamados loucos, nem de estender a eles os direitos formais de todos os cidadãos, mas, sobretudo,

[...] de buscar para a loucura algum cabimento na cidade - o que exige uma reinvençâo da cidade mesma, assim como outro pensamento da loucura [...] (LOBOSQUE, 2007, p. 35).

Tendo em vista a vulnerabilidade do público atendido pela saúde mental, o modelo de saúde mental busca se apropriar do espaço urbano numa perspectiva multifacetada de cidadania, conjugando a via dos direitos e da constituição de sujeitos políticos, atrelado ao espaço ancorado nas relaçóes cotidianas. No entanto, a aposta numa possível convivência com a diversidade depara-se com problemas estruturais, tais como o acesso aos serviços de proteção social, culturais, educacionais e laborativos que a vida pública deveria oferecer aos usuários de saúde mental. É diante desse cenário que a abordagem sociológica nos permite vislumbrar o espaço social nas suas açôes mais ordinárias como condição e meio de (re)produção das relações sociais, ou seja, lócus potencial de transformação da representação social e política da loucura na cidade.

$\mathrm{Na}$ seção seguinte apresenta-se sucintamente a história da reforma psiquiátrica e a consolidação da 
política nacional de saúde mental, com destaque para a territorialidade como um elemento de reorientação do modelo de assistência.

\section{Breve história da reforma psiquiátrica brasileira}

O início do processo de reforma psiquiátrica no Brasil ocorre no contexto da década 1970, a partir do qual se articulam frentes movimentalistas com plataformas democratizantes e relacionadas às políticas públicas, endereçadas à inclusão e alargamento dos direitos políticos e sociais. Nesse ambiente, o movimento de luta antimanicomial tangencia o movimento sanitarista, que configura uma frente de atores que se aglutinam partindo de uma concepçáo de saúde coletiva e de premissas de determinantes sociais de saúde rumo à crítica ao modelo então vigente. Sua atuação, plataforma e propostas reformistas influem na concepção do Sistema Único de Saúde - SUS, seus princípios e diretrizes, destacando-se a universalidade, a democratização e a participação, equidade do acesso à saúde, descentralização e integralidade na oferta dos serviços (MENICUCCI; BRASIL, 2010). Portanto, a partir do referido movimento moldou-se o SUS, no qual a política de saúde mental se insere.

A partir dos anos 1990, o SUS, orientado por uma gestão municipalizada, pela regionalização e hierarquização da rede de serviços de saúde, coloca o município num papel primordial na organização das redes de atenção à saúde. Esses princípios norteadores da política de saúde passam a reger, desde 2001, a política de saúde mental.

Além de comungar com as diretrizes da reforma sanitária, o processo de reforma psiquiátrica brasileiro tem uma história própria, inscrita num contexto internacional de mudanças pela superação da violência asilar, sob o paradigma da desinstitucionalização.

O conceito de desinstitucionalização tem como característica predominante a crítica epistemológica ao saber médico constituinte da psiquiatria e ao próprio conceito de doença mental (COSTA, 2003). Sob essa óptica, prevê-se a restituição da subjetividade do sujeito, na sua relação com as instituiçóes psiquiátricas e jurídicas, mais precisamente, e da possibilidade de recuperação da contratualidade, isto é, de posse de recursos para trocas sociais e para a cidadania social (SARACENO, 2001).

Assim, sob os pilares da descentralização, municipalização e integralidade da saúde, surgem experiências municipais de implementação de serviços de atenção à saúde mental comprometidos com as diretrizes da reforma, oferecendo novas modalidades assistenciais por meio dos serviços substitutivos Centros de Apoio Psicossociais - CAPS, Núcleos de Apoio Psicossocial - NAPS, CERSAMs, residências terapêuticas, centros de convivência, hospitais-dia, inclusão da saúde mental na atenção básica e no Programa de Saúde da Família - PSF, projetos de inserção no trabalho e cooperativas.

A concepção de território torna-se então elemento fundamental na proposta de reforma psiquiátrica, entendido como lócus da vida comunitária, e, por conseguinte, como força viva de relaçóes concretas e imaginárias que as pessoas estabelecem entre si, com os objetos, com a cultura, com as relaçóes que se dinamizam e se transformam (AMARANTE, 1998; BRASIL, 2011).

De uma forma bastante heterogênea, as práticas territoriais, em contraponto ao modelo hospitalocêntrico, tendem a enfraquecer o modelo de instituição total característico da assistência psiquiátrica tradicional, possibilitando um processo de restituição do poder contratual e de direito dos usuários da rede de atenção à saúde mental (TYKANORI, 1996 apud COSTA, 2003). Tais dispositivos, regidos sob a proposta da reabilitaçáo psicossocial, buscam definir um novo lugar social para o tratamento e a reabilitação das pessoas com sofrimento mental, promovendo açóes orientadas ao processo de inserçấo dessas pessoas na rede social. Trata-se de uma clínica que considera a complexidade, diversidade e singularidade do sofrimento psíquico e, por isso, propóe a utilização de múltiplos dispositivos clínicos como recursos que visam à aproximação, à construção de vínculos e de intervençóes que articulam o particular ao coletivo (MEOLA, 2000).

Em relação às "espacialidades," as premissas de substituição do modelo hospitalar para a rede de atenção à saúde mental abrem e alargam espaços, da reintegração do espaço doméstico à distensão para o espaço da cidade, com um campo de possibilidades relacionais e de apropriaçáo cotidiana para os usuários.

A concepçáo de território passa a ser um elemento fundamental no novo cenário estratégico do campo da saúde mental. Numa linha fenomenológica, o território é abordado no campo da saúde mental como uma força viva de relaçóes concretas e imaginárias que as pessoas estabelecem entre si, com os objetos, com a cultura, com as relaçóes que se dinamizam e se transformam. Tendo em vista o lugar que o território tem ocupado na transformação do modelo de saúde mental, os termos rede de serviços e rede de sociabilidade devem ser lidos de forma distinta, apoiada no pressuposto de que na dimensão espacial 
se ancoram a vida cotidiana, as políticas públicas e o exercício da cidadania.

Passados 12 anos de regulamentação da reforma psiquiátrica como política pública, o período atual caracteriza-se por dois movimentos simultâneos: a construção de uma rede de atenção à saúde mental substitutiva do modelo centrado na internaçáo hospitalar e a fiscalização e reduçáo progressiva e programada dos leitos psiquiátricos existentes.

\section{A construção dos dispositivos de saúde mental no território}

A partir da análise dos dados acerca dos serviços de saúde mental verifica-se que o Brasil dispóe de uma rede diversificada de serviços extra-hospitalares, denominada Rede de Atenção Psicossocial. Essa rede é composta por serviços de urgência dirigidos a crianças, adultos e usuários de álcool e drogas, denominados Centros de Atenção Psicossocial - CAPS, classificados em CAPS I, II e III, que se diferenciam pelo grau de cobertura (que varia entre $50 \mathrm{mil} \mathrm{hab.} \mathrm{e} 150 \mathrm{mil}$ hab.); CAPSAD - específico para o atendimento de álcool e drogas e CAPSI - para o público infantil; além das residências terapêuticas, das iniciativas de geração de renda, do programa de distribuição de renda (De volta para casa); dos centros de convivência e dos Consultórios de Rua (BRASIL, 2011).

A política de saúde mental busca atender aos usuários em várias demandas sociais que transcendem a especificidade da assistência para a garantia dos direitos sociais básicos, tais como moradia, renda, lazer, arte, trabalho, de forma mais ou menos intersetorial.

De uma forma geral, os dados referentes à rede de saúde mental demonstram uma tendência positiva de ampliação da estrutura de assistência extra-hospitalar. No período de 2001 a 2011, o número de CAPS aumentou de 295 para 1.650. Todavia esse número, que responde, em média, por $68 \%$ da cobertura assistencial no país, demonstra-se insuficiente, associado a baixo investimento na expansão dos dispositivos de reabilitaçáo psicossocial. A cobertura insuficiente de CAPS explica paradoxalmente a importância da permanência dos hospitais psiquiátricos nessa especialidade, diante da oferta de aproximadamente 35 mil leitos psiquiátricos em todo o território nacional (BRASIL, 2011).

Vale destacar a heterogeneidade da cobertura assistencial nas regióes brasileiras. As regiōes Nordeste e Sul apresentam uma maior cobertura de serviços extra-hospitalares, $77 \%$ e $82 \%$, respectivamente, enquanto a região Norte demonstra menor índice de cobertura, atingindo apenas 38\%. Isso porque a assistência no CAPS não suprime o sujeito do seu espaço doméstico e comunitário, sendo que a permanência mais prolongada nos serviços ocorre apenas na eminência de transtornos psíquicos severos e agudos. Embora sejam serviços de urgência, as açôes desenvolvidas pelos CAPS, muitas vezes, ultrapassam a estrutura física do equipamento, em busca da rede de suporte social dos usuários, considerando a singularidade, a história, a cultura e a vida cotidiana (BRASIL, 2011). Nesse caso, as concepçóes que respaldam o modelo de saúde mental se estreitam com as abordagens que enfatizam as potencialidades do espaço urbano, por meio da construçáo de redes de solidariedade. O contraponto dessa perspectiva é que a dimensão espacial também se apresenta como problema no que se refere à reprodução das desigualdades e da pobreza, sugerindo que a discussão da saúde mental deve ser problematizada na relação entre desigualdade social, políticas públicas e território.

Considerando que o retorno para o espaço doméstico nem sempre significa a volta para a família de origem, a criação dos serviços de residência terapêutica como modalidade assistencial substitutiva abre possibilidade de moradia para os usuários da saúde mental que se encontram em situação de abandono, devido à longa permanência em hospital psiquiátrico ou à dificuldade de convivência no meio familiar. A implantação dos serviços de residência terapêutica segue acompanhando o ritmo de fechamento dos leitos psiquiátricos, contudo a expansão do número de moradias no país ainda apresenta-se como um desafio. A cobertura desse dispositivo ainda é limitada e a implantação de moradia acompanha a heterogeneidade regional das demais ações em direção ao modelo substitutivo. Existem em funcionamento no país 596 módulos do Serviço Residencial Terapêutico, que assiste a 3.236 moradores. Fatores como idade, longo tempo de internação e comorbidades comumente presentes na população cronificada demandam SRTs adaptados e adequados, bem como maior número de cuidadores. O subfinanciamento do programa repercute negativamente no alcance de um padrão de cuidado mínimo exigido para os SRT (BRASIL, 2010).

Algumas cidades se destacam pela estruturação da rede de serviços de saúde mental, tais como Campinas e Belo Horizonte, que implementaram residências bem estruturadas e localizadas em bairros que facilitam a circulação dos usuários pela cidade e que, de fato, viabilizam a aproximaçáo dos usuários do território. 
No entanto, como já mencionado anteriormente, a redução dos procedimentos de internação de longa permanência não está diretamente relacionada à inserção social dessa população. Isso justifica a necessidade de incremento e consolidação da rede de atenção psicossocial territorializada, que responda não apenas pela assistência mas que atue de forma intersetorial, oportunizando novos acessos a bens e serviços, além da ampliação da interação desse público no espaço urbano.

Como atividade central da vida adulta, o trabalho é visto como possibilidade de ampliação da contratualidade e sociabilidade dos usuários da saúde mental no seu espaço de convivência. Sabe-se que o grau de formalidade das relaçóes de trabalho é um dos indicadores de inserção social (CASTEL, 1998). No caso das pessoas com transtornos mentais, não é incomum a interrupção de atividades laborativas ou educacionais após a incidência da patologia, ampliando a vulnerabilidade social desse público, tanto em função da renda, gerando maior dependência familiar ou do próprio Estado, quanto em relação às redes de suporte, devido à reduçáo dos vínculos sociais. O trabalho ainda é um elemento gerador de identidade e de cidadania, especialmente em países onde o Estado não garante o mínimo de seguridade social. Em relação a essa temática, o Ministério da Saúde, em parceria com a Secretaria Nacional de Economia Solidária/SENAES, do Ministério do Trabalho e Emprego, viabilizou a criação de uma política de incentivo técnico e financeiro para as iniciativas de inclusão social pelo trabalho. O repasse de incentivo financeiro aos estados e municípios proporcionou importante expansão dessas experiências, que somam hoje, de acordo com o Cadastro Nacional das Iniciativas de Inclusão Social pelo Trabalho (CIST), 640 iniciativas no país, das quais participam cerca de 6 mil usuários (BRASIL, 2010). No entanto, na prática há dificuldades de formação e consolidação de cooperativas para usuários da saúde mental. As limitaçóes são inerentes ao modelo cooperado de geração de renda, somadas às particularidades do público envolvido. Devido a esses desafios, muitas iniciativas não transpóem o desenho de pequenos grupos de produçáo, que geralmente surgem a partir das oficinas ofertadas pelos centros de convivência, que contam com pouca estrutura para seu funcionamento (COSTA, 2003). Ainda em relação às iniciativas de inserção pelo trabalho, parece correto afirmar que tais espaços sáo, de alguma forma, limitados quanto à diversidade de interaçôes e laços sociais propiciados, tendo em vista a homogeneidade do público que os frequentam, permanecendo normalmente vinculados ao universo dos usuários da saúde mental.

Outro equipamento que busca ampliar a circulação dos usuários na cidade são os centros de convivência, que oferecem espaços de arte, cultura e lazer em ambientes mais ou menos protegidos. Desde 2005, esses dispositivos públicos compóem a rede de saúde mental, neles são oferecidos espaços de sociabilidade, produção e intervenção na cidade às pessoas com transtornos mentais. Talvez esse equipamento tenha uma correlação mais direta com a construção de redes de sociabilidade para os usuários, justamente devido ao fato de que, além de permitir o inusitado e a criatividade, por meio da arte e da cultura alcança-se maior flexibilização nas regras de convivência e no pertencimento.

Com oferta restrita, os 51 centros de convivência do país ainda concentram-se nos grandes centros urbanos: mais da metade estão localizados em apenas três cidades, São Paulo (19), Campinas (7) e Belo Horizonte (9) (BRASIL, 2011).

\section{Considerações finais}

A série histórica dos dados sobre a saúde mental demonstra que a política de saúde mental implementada a partir do ano 2000, apesar de avanços regionalmente heterogêneos, não aponta para um retrocesso em direção ao modelo tradicional psiquiátrico, mas sim para a coexistência de dois modelos de assistência. No entanto, os dados acerca da implantação dos serviços de saúde mental reforçam o modelo de atenção psicossocial defendido como estratégia de reforma da assistência asilar.

Sem nos abstermos de uma preocupação com a qualidade dessa assistência ofertada, nem da eminente necessidade de fortalecimento político e epistemológico desse modelo de assistência, é possível inferir que os usuários da saúde mental estão de alguma forma ocupando novos espaços nas cidades.

As abordagens sociológicas mobilizadas, embora apresentem perspectivas de análise distintas acerca do espaço urbano, possibilitam uma leitura crítica e ao mesmo tempo dinâmica acerca do território como lócus de segregação e reprodução das desigualdades sociais, mas também com potencialidades para possíveis redes de solidariedade e mobilizações que podem minimizar os déficits de inclusividade social. Essa perspectiva dialética deve servir de lastro para as políticas sociais e para a política de saúde mental, encampando uma análise do espaço urbano, tanto numa perspectiva estrutural, que evidencia demandas dos usuários da saúde por melhoria nos 
serviços e no acesso a necessidades básicas, quanto como lócus das açôes mais ordinárias, condição e meio de (re)produção das relações sociais, ou seja, espaço potencial de transformação da representação social e política da loucura na cidade.

Diante dessas reflexôes, cabe indagar se a construção de dispositivos de saúde mental em bases territoriais favoreceu de fato a ampliaçáo e vivência de laços sociais que não estejam exclusivamente moldados pelos códigos da psiquiatria ou mesmo da rede de atençáo da política de saúde mental. Se o "pedaço" por eles apropriado, no qual tecem a trama de seu cotidiano, tem alargado as formas de participação desses indivíduos, seja no âmbito da convivência familiar e da amizade, seja nas atividades laborativas e de lazer, como concretização de um novo lugar social para a loucura.

Finalmente, há necessidade de uma investigação mais acurada acerca do modelo atual de saúde mental e de seus liames com a cidade, no que se refere às configurações relacionais que permeiam os vínculos entre os usuários e os profissionais de saúde, e, de forma mais ampla, entre eles e os grupos primários e secundários de convivência. Se, por um lado, os dados demonstram a ampliação dos serviços territoriais de saúde mental, por outro há carência de uma comprovaçáo empírica de que o desenho da política tenha ampliado a vivência de papéis e a sociabilidade do público assistido pelos serviços.

Por fim, o cabimento da loucura na cidade depende, inicialmente, de uma efetiva expansão dos serviços de saúde mental de bases territoriais, bem como de ampliação do acesso a bens e serviços náo necessariamente atrelados à saúde mental mas aos direitos sociais básicos da cidadania. Concomitantemente, espera-se que novas regras sociais de relacionamento não se restrinjam ao universo da saúde mental, mas que promovam novos encontros no espaço urbano, que mesmo com o tom do exótico e inusitado sejam marcados pelo respeito à diversidade e às diferenças. Caso contrário, corre-se o risco de os serviços de saúde mental continuarem a reproduzir ilhas de convivência entre os pares no território.

\section{Referências}

AMARANTE, P. Loucos pela vida: a trajetória da reforma psiquiátrica no Brasil. 2. ed. Rio de Janeiro: Fiocruz, 1998.
BRASIL, F. P. D. Território e territorialidade nas políticas sociais. In: CARNEIRO, C.; COSTA. B. Gestão social: o que há de novo? Belo Horizonte: Fundação João Pinheiro, 2004. p. 45-66. PMCid:PMC2716268

BRASIL. Ministério da Saúde. Secretaria de Atenção à Saúde. Saúde Mental em Dados 7, Brasília, 2010. (Informativo eletrônico, n. 7).

BRASIL. Ministério da Saúde. Secretaria de Atenção à Saúde. Saúde Mental em Dados 9, Brasília, 2011. (Informativo eletrônico, n. 9).

BRASIL, F. P. D. Cidade, redes e políticas sociais. In: LOBOSQUE, A. M.; SILVA, C. R. (Orgs.). Saúde mental: marcos conceituais e campos de prática. Belo Horizonte: Fórum Mineiro de Formação em Saúde Mental, 2013. p. 93-110.

CASTEL, R. As metamorfoses da questão social: uma crônica do salário. Petrópolis: Vozes, 1998.

CERTeaU, M. A invenção do cotidiano. Petrópolis: Vozes, 1996.

COSTA, L. A. O novo lugar do trabalho entre a sociedade e a loucura: estudo de caso de programas de geraçáo de renda para pessoas portadoras de sofrimento mental desenvolvidos em Campinas e Belo Horizonte. 2003. 163 f. Dissertação (Mestrado em Ciências Sociais)-Pontifícia Universidade Católica de Minas Gerais, Minas Gerais, 2003.

KOGA, D. Medidas de cidades: entre territórios de vida e territórios vividos. São Paulo: Cortez, 2003.

LEFEBVRE, H. The production of Space. Oxford: Blackwell, 1994.

LOBOSQUE, A. M. Um desafio à formação: nem teoria, nem o medo da invenção. In: LOBOSQUE, A. M. (Org.). Caderno Saúde Mental: a reforma psiquiátrica que queremos. Belo Horizonte: ESP-MG, 2007. p. 33-44.

LUPTON, R.; POWER, A. Social: exclusion and neighborhoods. In: HILLS, J. et al. (Eds). Understanting social exclusion. London: Oxford University, 2002. p. 118-140.

MAGNANI, J. G. M. Os pedaços do centro. Espaço \& Debates, São Paulo, v. 6, n. 17, p. 127-129, 1987.

MENICUCCI, T.; BRASIL, F. P. D. Construção de agendas e inovaçôes institucionais: análise comparativa da reforma sanitária e reforma urbana. Estudos de Sociologia, Araraquara, v. 15, n. 29, p. 369-396, 2010.

MEOLA, M. E. O campo da saúde mental e as tecnologias de cuidado: uma reflexão. Revista de Terapia Ocupacional da USP, São Paulo, v. 11, n. 1, p. 17-22, 2000.

PAUGAM, S. Desqualificação social: ensaio sobre a nova pobreza. São Paulo: Cortez, 2003.

SANTOS, B. S. A crítica da razão indolente. São Paulo: Cortez, 2000.

SARACENO, B. Libertando identidades: da reabilitaçấo psicossocial à cidadania possível. Rio de Janeiro: $\mathrm{Te}$ Corá, 2001. PMCid:PMC80930

\section{Contribuição dos Autores}

Ambas autoras participaram de todo o processo de elaboração do artigo (desenho, levantamento bibliográfico, análise e elaboração). 